\title{
HOUSEHOLDS’ HEALTH EXPENDITURES ON ACUTE GASTROENTERITIS IN MALAYSIA
}

\author{
Nur Nabila Jusoh ${ }^{1}$, Surianti Sukeri ${ }^{1 *}$, Hui Yee Chee ${ }^{2}$, Malina Osman ${ }^{2}$, Norashiqin Misni $^{2}$, Nur Raihana \\ Ithnin ${ }^{2}$, Asma' $\mathrm{Ali}^{3}$ and Christie Pei-Yee Chin ${ }^{4}$ \\ ${ }^{1}$ Department of Community Medicine, School of Medical Sciences, Universiti Sains Malaysia, 16160 Kota \\ Bharu, Kelantan, Malaysia \\ ${ }^{2}$ Faculty of Medicine and Health Sciences, Universiti Putra Malaysia, 43400 UPM Serdang, Selangor Darul \\ Ehsan, Malaysia \\ ${ }^{3}$ Faculty of Fisheries and Food Science, Universiti Malaysia Terengganu, 21030 Kuala Nerus, Terengganu, \\ Malaysia \\ ${ }^{4}$ Faculty of Computing and Informatics, Universiti Malaysia Sabah, 88300 Kota Kinabalu, Sabah, Malaysia
}

Corresponding author: Surianti Sukeri

Email: surianti@usm.my

\begin{abstract}
Acute gastroenteritis (AGE) causes significant health and economic burden on society. The aim of this study is to estimate households' direct and indirect expenditures on AGE and its predicted factors. This cross-sectional study was conducted between December 2019 and March 2020 using a bilingual proforma distributed using Survey Monkey among individuals with self-reported AGE in all 14 states of Malaysia. The finding revealed the average expenditure for a single episode of AGE was RM395.58 ( \pm SD 798.02). The mean indirect expenditure was higher at RM259.14 ( \pm SD 379.92) vs. direct expenditure of RM136.44 ( \pm SD 596.47). The highest expenditure was seen among those who obtained inpatient care. The multiple linear regression analysis showed that household income (RM0.13; 95\% Cl: 0.01, 0.27; $p=0.043$ ) and type of healthcare facility (private vs government) (RM1842.05; 95\% Cl: 395.13, 3288.98; $p=0.014)$ had significant association with households' total health expenditure on AGE. Acute gastroenteritis incurred substantial cost on all affected households regardless of care-seeking modalities. Interestingly, the main economic burden of AGE was the indirect cost of productivity loss; interpreted in terms of days away from work. In conclusion, AGE instigated economic burden on both households and employers. The household income and type of facility were found to be significant factors associated with the households' health expenditures due to AGE. This study recommends food safety awareness among the public and enforcement of safe food handling practices among food vendors and industries.
\end{abstract}

Keywords: Acute gastroenteritis, households' health expenditures, economic burden, productivity loss, cost analysis

\section{INTRODUCTION}

Acute gastroenteritis (AGE) is an illness characterized by inflammation of mucus membranes in the gastrointestinal tract. Approximately $70 \%$ of AGE cases is caused by virus such as rotavirus, while $10 \%$ to $20 \%$ of the cases caused by bacterial infection such as Salmonella and Campylobacter species ${ }^{1}$. It commonly presents with diarrhea and vomiting, but can also be accompanied by abdominal pain, nausea and fever $^{1,2}$. Due to the lack of a standard definition, a large population-based study in five countries suggested a standardized AGE definition of $\geq 3$ loose stool or any vomiting within 24 hours $^{3}$. This definition was acknowledged by the World Health Organization as an example of standard case definition for $\mathrm{AGE}^{4}$.

Globally, diarrhea leads to tremendous morbidity and mortality irrespective of age. The Global Burden of Diseases, Injuries and Risk Factors Study ${ }^{5}$ estimated that diarrhea had led to 1.31 million deaths in all age groups globally in 2015 . The same study ${ }^{5}$ reported that Malaysia had 385 deaths and 28305 DALYs attributable to diarrheal disease irrespective of age. In addition, approximately 61 deaths, 70,000 hospitalizations and 193,000 outpatient visits were reported among children under five years old in Malaysian healthcare facilities in $2013^{6}$.

The high magnitude of AGE burden is accompanied by significant economic loss. Health expenditure among households is one of the components required to determine the cost-of-illness of AGE. Its data serves many purposes such as to communicate the weight of the health problem for prioritization of resources, provide information on potential benefits if intervention is done and allow comparison between countries ${ }^{7}$.

Several studies demonstrated significant households' economic loss in both high-income country such as Canada ${ }^{8}$ and middle-income countries i.e. Thailand ${ }^{9}$ and Bangladesh $^{10}$. In Malaysia, Chai and Lee (2009), Lee et al (2012) and Loganathan et al (2015) had explored the direct and indirect households' expenditure related to $A G^{11-13}$. Nonetheless, their samples were limited to hospitalized pediatric cases. Since most patients with AGE did not seek treatment at 
healthcare facilities ${ }^{14}$, household economic surveys should also be done in the community instead of hospital setting to obtain more coverage and accurate burden of AGE. Meanwhile, another study by Azmi and Reginald (2015) only focused on the hospitalization fee, rather than complete direct and indirect expenditure ${ }^{15}$.

Further, factors associated with the households' expenditure on AGE was also minimally explored in the past. Factors that were ever studied in Malaysia were income status, residential area and presence of rotavirus infection. In comparison, research in other countries included factors such as age, severity of illness and place of seeking care. Generally, households' economic loss was associated with higher income groups, urban area, rotavirus as aetiologic agent, severe AGE presentation, elderly, inpatient care and use of private hospitals ${ }^{9-11}, 13,16,17$.

In addition to the above research gaps, no comprehensive household health expenditure irrespective of health-seeking activities on all age groups was ever conducted in Malaysia. Furthermore, the associated factors of households' expenditure were minimally explored locally. The aim of this study are twofold; 1 ) to estimate the direct and indirect expenditures of AGE among households in Malaysia, and 2) to determine the factors associated with households' health expenditure on AGE.

\section{METHODS}

A cross-sectional study using online survey method was conducted between December 2019 and March 2020. The survey proforma was developed using the Survey Monkey platform as it prevents double entry. Link to the survey was shared openly in the hope of reaching individuals in all 14 states of Malaysia.

The inclusion criteria were representatives of a household whose member(s) had a self-reported AGE that lasted less than 14 days within the past 12 months from the date of study participation. The representatives should be more than 18 years old Malaysian citizen who currently resided in Malaysia and able to understand either Malay or English language. The exclusion criterion was those who consented but did not complete the web-survey.

The sample size was determined by sample size calculator for estimation of a single mean ${ }^{18}$. The required sample size was 370 based on the standard deviation of 93 by previous literature ${ }^{13}$, $10 \%$ degree of precision, $5 \%$ level of significance and $10 \%$ non-response rate.

Convenience sampling was applied and the expenditure proforma was converted into an online survey made available in English and Malay languages. The proforma encompassed sociodemographic details of respondents, patient care, episode of illness, direct expenditure, and indirect expenditure related to AGE. Direct healthcare expenditure refers to all clinic and hospital charges paid out-of-pocket, over-thecounter medication, traditional medication and supplements. Direct non-healthcare expenditure refers to transportation expenditures to obtain care for AGE in health facilities, and expenditures for accommodation and food purchased while taking care of their sick family member at hospitals. Indirect expenditure is defined as productivity loss based on lost wages due to days away from work. Total households' health expenditure is the sum of direct healthcare, direct non-healthcare and indirect expenditures.

The link for the survey was distributed through emails, and social medias platforms such as Facebook and WhatsApp. A note was made to encourage recipients to share it within their circle of network. Implied consent was obtained if respondents ticked 'YES' on the consent statement. Respondents were then directed to the survey questions which took around five minutes to be completed.

\section{Data analysis}

Data were collected and analyzed by SPSS. Descriptive statistics was used to describe the demographic characteristics, characteristics of illness, direct healthcare expenditure, direct nonhealthcare expenditure and indirect expenditure. Simple regression was used to correlate the association between variables with the households' economic loss. Those variables with $\mathrm{p}<0.25$ were further analyzed using multiple regression to develop a model for total households' economic loss. Of note, for comparison with other international studies in the discussion, the researchers converted the expenditures to United States currency (USD); USD1=RM4.08 ${ }^{19}$.

\section{RESULTS}

Out of 382 respondents from all 14 states in Malaysia, 371 were reviewed and included in the analysis. Eleven respondents were excluded, as they did not complete the surveys thoroughly. The demographic characteristics of respondents are summarized in Table 1 . Overall, the majority of the respondents were female $(76.5 \%)$, Malay $(85.7 \%)$, married $(63.3 \%)$, university graduates $(85.2 \%)$ and government officials $(53.6 \%)$ with an average age of $33.04( \pm$ SD 8.51) years.

Majority $(51.6 \%)$ of respondents sought care from private health clinics. Between one to four members in a household were affected by AGE with a mean duration of 2.56 (1.63) days. Among those who were admitted for inpatient care, the average length of hospital stay was 2.50 (2.08) days (Table 2 ). 
Almost a third of the study respondents did not seek treatment $(n=125)$. The top two reasons were self-treatment at home $(n=51,46.8 \%)$ and perception that $A G E$ is a non-life threatening which will recover without any medical consultations ( $\mathrm{n}=49,45.0 \%)$.

The distribution of households' financial loss due to AGE is presented in Table 3. In general, the mean total health expenditure, regardless of the care seeking modalities, was RM395.58 ( \pm SD 798.02) per episode of AGE. The most significant expenditure drivers were ward charges and indirect expenditure from loss of wages. The total health expenditure was the highest among those who obtained inpatient care (RM1305.95 \pm SD 1982.18), and lowest among those who did not seek treatment $(\mathrm{RM} 244.90 \pm$ SD 367.54).

Table 1. Demographic characteristics of the sampled population $(n=371)$

\begin{tabular}{lll}
\hline Characteristics & $\mathrm{n}(\%)$ & Mean (SD) \\
\hline Gender & & \\
Male & $87(23.5 \%)$ \\
Female & $284(76.5 \%)$ & $33.04(8.51)$ \\
Age of respondent (years) & \\
Ethnicity & \\
Malay & $318(85.7 \%)$ \\
Chinese & $28(7.5 \%)$ \\
Indian & $11(3.0 \%)$ \\
Others & $14(3.8 \%)$ \\
Marital status & \\
Married & $235(63.3 \%)$ \\
Single & $128(34.5 \%)$ \\
Divorced/widowed & $8(2.2 \%)$ \\
Occupation & \\
Government employees & $199(53.6 \%)$ \\
Private sector employees & $52(14.0 \%)$ \\
Self-employed & $14(3.8 \%)$ \\
Pensioner & $7(1.9 \%)$ \\
Student / Housewife & $73(19.7 \%)$ \\
Unemployed & $26(7.0 \%)$ \\
Educational Level & \\
Secondary level & $29(7.8 \%)$ \\
Community College & $26(7.0 \%)$ \\
University & $316(85.2 \%)$ \\
Bottom 40\% & $155(41.8 \%)$ \\
Middle 40\% & $130(35.0 \%)$ \\
Top 20\% & $86(23.2 \%)$ \\
Medical Card insurance & $176(47.4 \%)$ \\
Yes & $195(52.6 \%)$ \\
\hline Notal number of households & \\
\hline
\end{tabular}


Table 2. Characteristics of illness and utilization of healthcare services

\begin{tabular}{|c|c|c|}
\hline Characteristics & n (\%) & Mean (SD) \\
\hline $\begin{array}{l}\text { Place of treatment }(\mathrm{n}=246) \\
\text { Private health clinic } \\
\text { Government health clinic } \\
\text { Government hospital } \\
\text { Private hospital }\end{array}$ & $\begin{array}{l}127(51.6 \%) \\
79(32.1 \%) \\
25(10.2 \%) \\
15(6.1 \%)\end{array}$ & \\
\hline $\begin{array}{c}\text { Patient status }(\mathrm{n}=246) \\
\text { Outpatient } \\
\text { Inpatient }\end{array}$ & $\begin{array}{l}206(83.7 \%) \\
40(16.3 \%)\end{array}$ & \\
\hline Number of households with AGE & $371(100 \%)$ & $1.52(0.78)$ \\
\hline Duration of AGE & $371(100 \%)$ & $2.56(1.63)$ days \\
\hline Length of hospital stay & $40(10.8 \%)$ & $2.50(2.08)$ days \\
\hline Days away from work & $371(100 \%)$ & $1.33(1.62)$ days \\
\hline
\end{tabular}

Table 3: Distribution of households' health expenditure due to AGE (in RM)

\begin{tabular}{|c|c|c|c|c|c|c|c|c|}
\hline \multirow{2}{*}{ Expenditure } & \multicolumn{2}{|c|}{$\begin{array}{l}\text { Did not seek } \\
\text { treatment }\end{array}$} & \multicolumn{2}{|c|}{ Outpatient care } & \multicolumn{2}{|r|}{ Inpatient care } & \multicolumn{2}{|r|}{ Overall } \\
\hline & $\mathbf{N}$ & Mean ( \pm SD) & $N$ & Mean ( \pm SD) & $\mathrm{n}$ & Mean ( \pm SD) & $\mathbf{N}$ & Mean ( \pm SD) \\
\hline $\begin{array}{l}\text { Direct healthcare } \\
\text { Ward Charges } \\
\text { Clinic Fee } \\
\text { Traditional medication } \\
\text { Supplement } \\
\text { Over the counter } \\
\text { medication }\end{array}$ & $\begin{array}{c}- \\
- \\
94 \\
97 \\
125\end{array}$ & $\begin{array}{c}- \\
- \\
0.52(2.56) \\
17.21(43.59) \\
7.48(14.05)\end{array}$ & $\begin{array}{l}- \\
204 \\
128 \\
135 \\
206\end{array}$ & $\begin{array}{c}- \\
35.97(42.18) \\
4.45(16.45) \\
18.73(37.65) \\
10.11(28.85)\end{array}$ & $\begin{array}{c}37 \\
- \\
33 \\
36 \\
40\end{array}$ & $\begin{array}{c}743.43(1722.96) \\
- \\
2.88(10.97) \\
21.39(46.73) \\
14.93(35.03)\end{array}$ & $\begin{array}{l}40 \\
204 \\
255 \\
268 \\
371\end{array}$ & $\begin{array}{c}687.68(1667.21) \\
35.97(42.18) \\
2.80(12.49) \\
18.54(41.02) \\
9.75(25.71)\end{array}$ \\
\hline $\begin{array}{l}\text { Direct non-healthcare } \\
\text { Transportation } \\
\text { Accommodation } \\
\text { Food }\end{array}$ & $\begin{array}{l}- \\
- \\
-\end{array}$ & $\begin{array}{l}- \\
- \\
-\end{array}$ & $\begin{array}{c}204 \\
- \\
-\end{array}$ & $\begin{array}{c}9.23(9.01) \\
- \\
-\end{array}$ & $\begin{array}{l}37 \\
37 \\
37\end{array}$ & $\begin{array}{l}56.54(97.75) \\
17.24(48.40) \\
50.41(92.48)\end{array}$ & $\begin{array}{c}244 \\
40 \\
40\end{array}$ & $\begin{array}{l}16.29(42.13) \\
15.95(46.73) \\
16.63(89.87)\end{array}$ \\
\hline $\begin{array}{l}\text { *Total Direct } \\
\text { expenditure }\end{array}$ & & $21.23(45.36)$ & & $69.92(71.56)$ & & $839.10(1664.21)$ & & $136.44(596.47)$ \\
\hline $\begin{array}{l}\text { Indirect expenditure } \\
\text { (Productivity loss) } \\
\text { Loss of wages }\end{array}$ & 125 & $\begin{array}{c}223.67 \\
(349.52)\end{array}$ & 206 & $240.33(352.24)$ & 40 & 466.85 (527.83) & 371 & 259.14 (379.92) \\
\hline $\begin{array}{l}\text { Total households' } \\
\text { expenditure }\end{array}$ & & $\begin{array}{l}244.90 \\
(367.54)\end{array}$ & & $\begin{array}{c}310.24 \\
(370.59)\end{array}$ & & $\begin{array}{c}1305.95 \\
(1982.18)\end{array}$ & & $\begin{array}{c}395.58 \\
(798.02)\end{array}$ \\
\hline
\end{tabular}

The average waiting time when seeking treatment at clinic was 50.52 ( \pm SD 45.59) minutes. Eightyeight respondents who were pensioners, students, homemakers and unemployed reported they were unable to carry out daily activities for an average of $1.94( \pm$ SD 1.86) days.

Table 4 shows the simple linear regression of socio-demographic, episode of illness and patient care factors associated with total households' economic loss due to AGE. Based on the univariable analysis, significant variables with $\mathrm{p}$ - value of less than 0.25 were all factors except ethnicity, ownership of medical card and number of household members affected by AGE. Thus, these variables were excluded in the multiple linear regression analysis.

The multiple linear regression analysis showed that total household income and type of facility (private vs government) had a significant linear relationship to households' health expenditure. The final model was statistically significant with $\mathrm{F}$ $(2,34)=9.099 ; p<0.05$ and it explained the total 
variance of $34.9 \%$ of the household economic loss due to AGE. It showed that with an additional of RM1 increase in household income will increase households' total health expenditures due to AGE by RM0.14 (95\% Cl: 0.01, 0.27; p=0.043) when the type of facility was adjusted. Households' health expenditure due to AGE was also predicted to be
RM1842.05 (95\% Cl: 395.13, 3288.98; $p=0.014$ ) higher for those seeking treatment in private facilities compared to government facilities when total household income was adjusted. Table 5 shows the final multiple linear regression model of this study.

Table 4: Simple linear regression of socio-demographic, episode of illness and patient care factors associated with households' economic loss due to AGE.

\begin{tabular}{|c|c|c|c|}
\hline Variables & Crude $b(95 \% \mathrm{Cl})$ & P-value* & $r^{2}$ \\
\hline $\begin{array}{l}\text { Ethnicity } \\
\text { Malay }\end{array}$ & & & 0.002 \\
\hline $\begin{array}{l}\text { Chinese } \\
\text { Indian }\end{array}$ & $\begin{array}{l}-113.43(-457.82,230.97) \\
133.44(-402.35,669.23)\end{array}$ & $\begin{array}{l}0.518 \\
0.625\end{array}$ & \\
\hline Others & $53.37(-423.72,530.46)$ & 0.826 & \\
\hline $\begin{array}{l}\text { Marital status } \\
\text { Married }\end{array}$ & & & 0.040 \\
\hline Single & $-372.68(-560.69,-184.67)$ & $<0.001$ & \\
\hline Divorced & $-159.18(-774.49,456.13)$ & 0.611 & \\
\hline $\begin{array}{c}\text { Highest education } \\
\text { University }\end{array}$ & & & 0.007 \\
\hline College & $-121.90(-476.99,233.18)$ & 0.500 & \\
\hline Secondary school & $-257.91(-595.60,79.78)$ & 0.134 & \\
\hline Occupation & & & 0.061 \\
\hline $\begin{array}{l}\text { Unemployed } \\
\text { Student/ Housewife } \\
\text { Self-employed } \\
\text { Retiree }\end{array}$ & $\begin{array}{l}62.53(-325.63,450.68) \\
669.93(106.54,1233.32) \\
257.36(-466.33,981.06)\end{array}$ & $\begin{array}{l}0.752 \\
0.020 \\
0.485\end{array}$ & \\
\hline Government sector & $482.83(128.42,837.25)$ & 0.008 & \\
\hline Private sector & $627.08(218.86,1035.29)$ & 0.003 & \\
\hline $\begin{array}{l}\text { Children under } 5 \text { years } \\
\text { No }\end{array}$ & & & 0.007 \\
\hline Yes & $196.68(-45.19,438.55)$ & 0.111 & \\
\hline $\begin{array}{c}\text { Medical card insurance } \\
\text { Yes }\end{array}$ & & & 0.003 \\
\hline $\begin{array}{l}\text { No } \\
\text { Total household income }\end{array}$ & $\begin{array}{l}-95.58(-276.65,85.49) \\
0.06(0.04,0.07)\end{array}$ & $\begin{array}{l}0.300 \\
<0.001\end{array}$ & 0.094 \\
\hline Household Size & $-35.11(-71.95,1.72)$ & 0.062 & 0.010 \\
\hline Duration of illness & $123.20(68.86,177.53)$ & $<0.001$ & 0.051 \\
\hline $\begin{array}{l}\text { Number of household members with } \\
\text { AGE }\end{array}$ & $47.27(-69.01,163.54)$ & 0.425 & 0.002 \\
\hline
\end{tabular}

*Simple linear regression

Table 5: Multiple linear regression of socio-demographic, episode of illness and patient care factors associated with households' health expenditure due to AGE.

\begin{tabular}{lccccc}
\hline Variables & Unstd. B & $\begin{array}{c}\text { Std. B } \\
\text { Coefficient }\end{array}$ & $\mathbf{9 5 \% ~ C l}$ & T & P-value \\
\hline Total household income & 0.136 & 0.390 & $0.01,0.27$ & 2.099 & 0.043 \\
$\begin{array}{l}\text { Type of health facility } \\
\text { (Private vs Government) }\end{array}$ & 1842.054 & 0.316 & $395.13,3288.98$ & 2.587 & 0.014 \\
\hline
\end{tabular}

\section{Constant $=-175.67$}

Forward and stepwise method Adjusted $R^{2}=0.310$

Model assumptions were met

No interaction and multicollinearity $(\mathrm{VIF}<10)$ 


\section{DISCUSSION}

The study aimed to estimate the direct and indirect expenditures to obtain households' health expenditure of AGE in Malaysia irrespective of the mode of transmission or type of infectious agent causing AGE. We discovered that the average households' health expenditures over AGE regardless of their utilization rates of healthcare services was RM395.58 (USD96.96). However no comparison can be made with previous studies since its focus was on the economic burden of AGE among pediatric patients in Malaysia.

This study also examined households' health expenditure following the type of health facility utilized by patients. Compared with households whose members did not seek treatment or seek outpatient care, the total households' health expenditure was the highest among hospitalized patients amounting to RM1305.95 (USD320.09). It could be justified by additional costs contributed by ward charges, transportation, accommodation, and food. Severe hospitalized AGE cases necessitate higher expenditures from over-thecounter medicines, traditional medication and supplements, as compared to the other two groups. Additionally, severe cases also resulted in more indirect expenditure with more days away from work. Our finding was higher compared to the median household expenditure of USD252.86 reported by Lee et al in $2009^{11}$. The difference is expected since food, accommodation, supplements and traditional medication were excluded in the older study.

In 2015, Loganathan et al reported the sum of direct and indirect expenditure was USD35 for hospitalized AGE cases from the Hospital Sultanah Nur Zahirah, Kuala Terengganu ${ }^{13}$. In contrast, this study found the total direct and indirect expenditure for inpatient care in government hospital was USD 133.73. It is possible that the difference may be due to omission of several expenditure components and missing data of direct hospitalization charges. The same study showed that the total expenditure in University Malaya Medical Centre, UMMC was lower (USD 224) compared to this study. The difference was contributed mainly by hospital charges since UMMC was a university hospital that provides subsidized care.

On the other hand, Azmi and Reginald (2015) in their study reported the expenditure for hospitalization fee was USD350 ${ }^{15}$, higher than those observed in this study (RM743.43, USD182.21). Possible reasons for the higher expenditure in their study were due to the study location in urban areas and that most of their samples were admitted to private hospitals.

Pertaining to indirect expenditure of AGE, only days away from work was considered in this study.
This study found that the average days off from work was minimal; 1.33 ( \pm SD 1.62) days. However, the waiting time while seeking treatment at health facilities ranged between five minutes to five hours, excluding the return trip travelling time to the health facilities. Therefore, for employed respondents, although AGE did not cause significant number of days away from work, their employers lost a substantial amount of their employees' time at work to seek treatment which consequently reduced their productivity.

Unfortunately, AGE also posed negative impact on non-working groups such as pensioners, students, homemakers and unemployed. It caused disruption of their daily activities for an average of 1.94 ( \pm SD 1.86) days. To add, in 2020, Malaysia was shocked by a food poisoning outbreak due to consumption of contaminated local dessert in Kuala Terengganu. Most victims experienced diarrhea, vomiting and fever. Out of the 99 cases, 35 were treated in HSNZ, ten were treated in private hospitals, 23 received outpatient care, while the remaining did not seek treatment ${ }^{20}$. Unfortunately, this food poisoning outbreak also had resulted in one death case ${ }^{21}$. Apart from the mortality and morbidity, the outbreak incurred financial burden on victims; a family reported spending almost RM20,000 for healthcare-related expenditure since 16 of his family members were affected by the food poisoning ${ }^{22}$. It further reaffirmed our findings that AGE does cause significant impact on family finances.

In addition, this study discovered the type of healthcare facility attended by households was significantly associated with the total households' economic loss. The utilization of care in the private health facility imposed higher households' expenditure compared to that of the public health facility. This result was consistent with the findings by Burke and Smith (2014) who reported that families who were admitted in private hospitals had significantly higher financial burden as compared to admissions in public hospital (USD59 vs USD20) ${ }^{17}$. High charges by the private health sectors apparently did not hinder patients from seeking care at their facilities. There is a public perception that quality of care differs between public and private healthcare facilities. Private hospitals are equipped with advanced medical equipment and more medical specialists, allowing patients to choose their doctor and obtain care with shorter waiting time ${ }^{23,24}$.

This study also revealed that household income had a significant positive linear relationship with household total economic loss of AGE. It means that for every AGE episode, the higher the household income, the greater the total households' financial loss. This finding is in agreement with a study by Loganathan et al (2015) who observed higher OOP expenditure among higher income hospitalized pediatric patients in both Kuala Lumpur and Kuala 
Terengganu ${ }^{13}$. Rheingans et al (2012) also found that the total household expenditures were lower among the lowest wealth quintile in three South Asian countries ${ }^{16}$.

Such a scenario is expected since individuals from higher-income group have higher purchasing power. They can afford to purchase expensive over-the-counter drugs, traditional medicines, and supplements. They also prefer to obtain care at private healthcare facilities which they perceived to be of better quality. Also, since loss of wages was based on households' monthly income, it is anticipated that higher income would naturally result in higher wage loss.

Several limitations should be noted in this study. Firstly, the study relied on self-reported illness which was bound for recall bias. Secondly, a major challenge in statistical models in cost analysis is the skewed data due to abundance of data with zero $\cos \mathrm{t}^{25}$. However, according to the central limit theorem, the violation of normality assumption should not be a problem with sample size more than 30 or $40^{26,27}$. Therefore, with a large sample size $(n=371)$ in this present study, we analyzed the data using parametric procedures despite the abundance of zero cost.

\section{CONCLUSION}

Acute gastroenteritis incurred significant economic implications on affected households irrespective of the utilization of healthcare services. Financial loss was the greatest among those who were admitted to the hospital. Indirect expenditure from productivity loss incurred from days away from work remained the highest contributor to the economic loss due to AGE. Public health intervention is crucial in the prevention and health promotion of AGE in Malaysia. The study findings provide a basis for policymakers to enhance food safety awareness among the public and motivate the preparation, handling, distribution, sale and consumption of safe, high quality food among food vendors and industries. The Food Act 1983 should be imposed to monitor food sales from the increasing number of unregistered food vendors during the Covid-19 pandemic. Failure to do so may lead to more AGE events thus harming household economies, impeding socioeconomic development, tourism and trade.

\section{Acknowledgement}

We wish to thank all respondents for their participation in this study.

\section{Competing interests}

The authors declare that they have neither competing interests nor financial disclosure

\section{Funding}

This study was funded by the Malaysian Research University Network (MRUN) grant (UPM/800-
4/11/MRUN/2018/5539240) awarded by the Ministry of Higher Education Malaysia

\author{
Author contributions \\ All authors read and approved the final \\ manuscript.
}

\section{REFERENCES}

1. Chow CM, Leung AK, Hon KL. Acute gastroenteritis: From guidelines to real life. Clin Exp Gastroenterol. 2010;3:97112.

2. Catherine AC, Aftab Z. Gastroenteritis in children: Part I diagnosis. American family physician. 2012;85(11):1059-62.

3. Majowicz SE, Hall G, Scallan E, Adak GK, Gauci C, Jones TF, et al. A common, symptom-based case definition for gastroenteritis. Epidemiology and infection. 2008;136(7):886-94.

4. WHO. WHO Initiative to Estimate the Global Burden of Foodborne Diseases. 2007.

5. Troeger C, Forouzanfar M, Rao P, Khalil I, Brown A, Jr R, et al. Estimates of global, regional, and national morbidity, mortality, and aetiologies of diarrhoeal diseases: A systematic analysis for the Global Burden of Disease Study 2015. The Lancet Infectious Diseases. 2017;17(9):909-48.

6. Loganathan $\mathrm{T}, \mathrm{Ng} \mathrm{CW}$, Lee WS, Jit M. The hidden health and economic burden of rotavirus gastroenteritis in Malaysia: An estimation using multiple data sources. Pediatric Infectious Disease Journal. 2016;35(6):601-6.

7. Jo C. Cost-of-illness studies: concepts, scopes, and methods. Clin Mol Hepatol. 2014;20(4):327-37.

8. Saux N, Bettinger J, Déry P, Embree J, Vaudry W, Halperin S, et al. The hidden costs and characteristics of childhood rotavirus emergency visits in Canada. The Pediatric infectious disease journal. 2012;31(2):159-63.

9. Rochanathimoke O, Riewpaiboon A, Tharmaphornpilas $P$, Jiamsiri $S$, Thavorncharoensap M, Postma MJ. Economic burden of rotavirus diarrhea in Thailand: Report from a pilot study on rotavirus vaccination. Vaccine. 2019;37(4):587-94. 
10. Sarker AR, Sultana M, Mahumud RA, Ali N, Huda TM, Salim Uzzaman $M$, et al. Economic costs of hospitalized diarrheal disease in Bangladesh: A societal perspective. Global health research and policy. 2018;3:1.

11. Chai PF, Lee WS. Out-of-pocket costs associated with rotavirus gastroenteritis requiring hospitalization in Malaysia. Vaccine. 2009;27 Suppl 5:F112-5.

12. Lee WS, Chai PF, Ismail Z. Impact on parents during hospitalisation for acute diarrhoea in young children. Singapore medical journal. 2012;53(11):755-9.

13. Loganathan $\mathrm{T}$, Lee $\mathrm{WS}$, Lee $\mathrm{KF}$, Jit $\mathrm{M}, \mathrm{Ng}$ CW. Household catastrophic healthcare expenditure and impoverishment due to rotavirus gastroenteritis requiring hospitalization in Malaysia. PLOS ONE. 2015;10(5).

14. Tee GH, Kaur G, Ramanathan P, Amal NM, Chinna K. Health seeking behavior among Malaysians with acute diarrheal disease. Southeast Asian Journal of Tropical Medicine and Public Health. 2011;42(2):424-35.

15. Azmi, Reginald P. Experience and cost of pediatric gastroenteritis to families: A survey of Malaysian and Vietnamese parents. Journal of Gastroenterology, Pancreatology and Liver Disorders. 2015;2(1):1-8.

16. Rheingans R, Kukla M, Faruque AS, Sur D, Zaidi AK, Nasrin D, et al. Determinants of household costs associated with childhood diarrhea in 3 South Asian settings. Clinical Infectious Disease. 2012;55 Suppl 4:S32735.

17. Burke RM, Smith ER, Dahl RM, Rebolledo PA, del Carmen Calderón M, Cañipa B, et al. The economic burden of pediatric gastroenteritis to Bolivian families: A cross-sectional study of correlates of catastrophic cost and overall cost burden. BioMed Central Public Health. 2014;14(1):642.

18. Najib MY. Sample size calculator for estimation of a single mean: University Sains Malaysia; 2015. http://www.medic.usm.my/biostat/artic les/121-tools-nmy.html. (accessed 9 November 2019)
19. Census and Economic Information Centre. Malaysia exchange rate against USD: Monthly average Singapore: CEIC; 2020. https://www.ceicdata.com/en/malaysia /foreign-exchange-rates/exchange-rateagainst-us-monthly-average. (accessed 9 May 2020)

20. Bernama. Terengganu food poisoning victims climb to 99 Malaysia: The Sun Daily; 2020. https: / /www.thesundaily.my/local/tere ngganu-food-poisoning-victims-climb-to99-EA2460215. (accessed 3 June 2020)

21. Zolkiply ZI. Mangsa puding buih pertama meninggal: Harian Metro; 2020. https: / /www.hmetro.com.my/utama/20 20/06/585487/mangsa-puding-buihpertama-meninggal. (accessed 3 June 2020)

22. Salim Z. Serik makan puding buih: Harian Metro; 2020. https://www.hmetro.com.my/mutakhir/ 2020/05/583806/serik-makan-pudingbuih-metrotv. (accessed 3 June 2020)

23. OECD, Organization WH, Barber SL, Lorenzoni L, Ong P. Price setting and price regulation in health care. 2019.

24. Cheong KC, Tey N, Rasiah R. The population development relationship in Malaysia. Revisiting Malaysia's population development nexus: Faculty of Economics and Administration, University of Malaya; 2016. p. 1-14.

25. Gilleskie DB, Mroz TA. A flexible approach for estimating the effects of covariates on health expenditures. Journal of Health Economics. 2004;23(2):391-418.

26. Pallant J. SPSS survival manual: A step by step guide to data analysis using SPSS for Windows version 15. Third ed. Sydney: McGraw Hill; 2007.

27. Elliot AC, Woodward WA. Statistical analysis quick reference guidebook: With SPSS examples. First ed. London: Sage Publication; 2007. 